\title{
The effect of topical benzamil and amiloride on nasal potential difference in cystic fibrosis
}

\author{
H.C. Rodgers, A.J. Knox
}

\begin{abstract}
The effect of topical benzamil and amiloride on nasal potential difference in cystic fibrosis. H.C. Rodgers, A.J. Knox. (C) ERS Journals Ltd 1999.

ABSTRACT: The electrochemical defect in the bronchial epithelium in cystic fibrosis (CF) consists of defective chloride secretion and excessive sodium reabsorption. The sodium channel blocker, amiloride, has been shown to reversibly correct the sodium reabsorption in CF subjects, but long term studies of amiloride have been disappointing due to its short duration of action. Benzamil, a benzyl substituted amiloride analogue, has a longer duration of action than amiloride in cultured human nasal epithelium. The results of the first randomized, placebo controlled, double blind, crossover study are reported here comparing the effects of benzamil and amiloride on nasal potential difference (nasal PD) in CF.

Ten adults with $\mathrm{CF}$ attended on three occasions. At each visit baseline nasal PD was recorded, the drug (amiloride $1 \times 10^{-3} \mathrm{M}$, benzamil $1.7 \times 10^{-3} \mathrm{M}$, or $0.9 \%$ sodium chloride) was administered topically via a nasal spray, and nasal PD was measured at 15, $30 \mathrm{~min}, 1,2,4$ and $8 \mathrm{~h}$. Results were expressed as maximum change in nasal PD from baseline (PDmax), time for PDmax to return to 50\% of baseline (t0.5), and the area under the curve (AUC).

PDmax values for benzamil $(20.6 \pm 0.9 \mathrm{mV})$ and amiloride $(20.3 \pm 1.6 \mathrm{mV})$, were similar. The duration of effect was much longer for benzamil as measured as either AUC or t0.5 AUC values were $11.8 \pm 1.6 \mathrm{mV}$ for benzamil, $2.8 \pm 0.4 \mathrm{mV}$ for amiloride and $0.6 \pm 0.4 \mathrm{mV}$ for placebo. The AUC value for benzamil was significantly greater than amiloride (95\% confidence interval (CI) for the difference $5.3-12.7 \mathrm{mV}, \mathrm{p}<0.0001)$. t0.5 values were $4.3 \pm 0.7 \mathrm{~h}$ for benzamil and $0.6 \pm 0.1 \mathrm{~h}$ for amiloride $(95 \%$ CI for the difference 2.0-5.3 h, p<0.001).

It is concluded that benzamil has a similar maximal effect to amiloride but a more prolonged duration of action on nasal potential difference in cystic fibrosis. Benzamil may be a useful sodium channel blocker for the long-term treatment of the biochemical defect in the lungs of patients with cystic fibrosis.
\end{abstract}

Eur Respir J 1999; 14: 693-696.

Respiratory Medicine Unit, City Hospital, Hucknall Road, Nottingham, NG5 IPB.

Correspondence: A.J. Knox

Respiratory Medicine Unit

Clinical Sciences Building

City Hospital

Hucknall Road

Nottingham NG5 1PB

UK

Fax: 01159602140

Keywords: Amiloride

benzamil

cystic fibrosis

nasal potential difference

Received: January 131999

Accepted after revision November 71999

This study was supported by the UK Cystic Fibrosis Trust.
The lung disease in cystic fibrosis $(\mathrm{CF})$ is thought to be the result of abnormal ion flux across bronchial epithelia. This consists of reduced apical chloride secretion by the defective cystic fibrosis transmembrane conductance regulator (CFTR), the product of the CF gene, and a two-fold increase in sodium absorption through apical epithelial sodium channels $(\mathrm{ENaC})$ [1-3]. Attempts to correct the abnormal ion flux have consisted of gene therapy to replace the function of defective CFTR, or pharmacological therapy with chloride channel openers or sodium channel blockers. The nasal epithelium provides a useful site to test novel potential therapies as it is readily accessible and nasal potential difference (PD) can be easily and reproducibly measured [4-7].

Early attempts to correct the increased sodium reabsorption in CF used amiloride, a pyrazinoylguanidine [8], which reversibly inhibits $\mathrm{ENaC}$ [9]. Amiloride has been shown to reduce sodium reabsorption transport across airway epithelia and reduce nasal PD in healthy subjects and patients with $\mathrm{CF}[1,2]$ but three randomized controlled trials of long term administration of aerosolized amiloride on lung function produced conflicting and disappointing results [10-12]. The most likely reason for the lack of benefit is that amiloride has a very short duration of action and is cleared rapidly from the lungs [13-16]. Longer acting sodium channel blockers might, therefore, prove more effective.

Benzamil, a benzyl substituted amiloride analogue, is a longer acting and more potent sodium channel inhibitor than amiloride in cultured human CF nasal epithelium [8, 17]. An open uncontrolled pilot study has suggested that benzamil may have a longer duration of action on nasal PD than amiloride when given topically [18]. The authors have therefore performed a randomized, double blind, placebo controlled study to compare the effects of topically applied benzamil and amiloride on nasal PD in CF.

\section{Material and Methods}

\section{Subjects}

Ten subjects, median age 22 yrs (range 18-30) were recruited from the adult clinic at Nottingham City Hospital. All had elevated sweat sodium $\left(>60 \mathrm{mmol} \cdot \mathrm{L}^{-1}\right)$ and 
chloride $\left(>70 \mathrm{mmol} \cdot \mathrm{L}^{-1}\right)$ concentrations as well as clinical and radiological features consistent with the diagnosis of $\mathrm{CF}$. The genotype of all but one subject were known: 3 patients were homozygous for $\Delta \mathrm{F} 508,3$ patients had one $\Delta \mathrm{F} 508$ the other mutation being unknown and there were three patients with $\Delta \mathrm{F} 508 / \mathrm{Q} 1493 \mathrm{X}, \Delta \mathrm{F} 508 / 621+1 \mathrm{G}>\mathrm{T}$ and $\mathrm{G} 551 \mathrm{D} / 621+1 \mathrm{G}>\mathrm{T}$ respectively. Subjects were excluded from the study if there was a previous history of nasal surgery, current nasal symptoms, or if they had had a pulmonary exacerbation or upper respiratory tract infection within the preceding 2 weeks. The study was performed between September 1997 and July 1998. The study protocol was approved by the Nottingham City Hospital Ethics Committee and all subjects gave written informed consent.

\section{Nasal potentiaI difference measurement}

Nasal PD was measured using an adaptation of the method described by MidDLETon et al. [19] and used previously by the current authors [7]. Briefly, the exploring electrode consisted of a paediatric urinary catheter (Foley size 8) filled with electrode cream (Signa Creme; Parker Laboratories Inc, Orange, NJ, USA), connected to a high impedance voltmeter (RS Components, Birmingham, AL, USA) by a silver/silver chloride electrode (Specialized Laboratory Equipment, South Croydon, UK). Skin drilling with a diamond tip dental burr (Kent dental, Gillingham, UK) was performed on the right forearm to superficially abrade the skin. A silver/silver chloride electrode (Specialized Laboratory Equipment) was placed over the abraded skin and electrode cream injected through a hole in the top of the electrode to allow contact. The reference electrode was connected to the same voltmeter. Before recordings were made the offset of the electrodes was measured and appropriate corrections made. The exploring electrode was passed along the floor of the nose without direct vision. The catheter was advanced until the maximal PD had been passed and then gradually withdrawn. The highest voltage stabilized for $10 \mathrm{~s}$, was recorded. Three measurements were made from each nostril and a mean for each side obtained. The mean of the two sides was used to give the nasal PD reading for each subject at each time point. The exploring catheter was removed after each reading. All nasal PDs were lumen negative with respect to the reference electrode. The authors have previously shown that nasal PD measurement is repeatable in their hands [7].

\section{Study drugs}

Benzamil and amiloride were purchased from Sigma (Poole, Dorset, UK). Amiloride $\left(1 \times 10^{-3} \mathrm{M}\right)$ and benzamil $\left(1.7 \times 10^{-3} \mathrm{M}\right)$ solutions were prepared at their limit of solubility in $0.9 \%$ sodium chloride [17]. $0.9 \%$ sodium chloride was used as placebo.

\section{Protocol}

The study had a randomized, double blind, placebo controlled, crossover design. Randomization was performed by the Nottingham City Hospital Pharmacy using an in house random number randomization schedule. The treatment order for each subject was assigned randomly according to the randomization schedule above. The study drug was made up in the pharmacy and both subject and investigator were blinded to the nature and order of treatments. Subjects attended at the same time of day on three occasions each separated by $\geq 48 \mathrm{~h}$. Subjects were asked to omit any inhalers or nebulized drugs on the study days. Baseline nasal PD (basal PD) was measured, $0.4 \mathrm{~mL}$ of the study drug (benzamil, amiloride) or placebo $(0.9 \%$ sodium chloride) was applied topically to each nostril using a nasal spray (sterilized Beconase ${ }^{\mathbb{B}}$ 200; Allen and Hanburys, Uxbridge, UK) and repeat nasal PD measurements were made at 15 and $30 \mathrm{~min}, 1,2,4$ and $8 \mathrm{~h}$. The sterilization procedure allowed the nasal spray to be used as a passive carrier.

\section{Analysis}

All values are expressed as mean \pm SEM. Baseline nasal PD values were compared by two way analysis of variance (TWAOV) (SPSS Inc., Chicago IL, USA). The maximal change in nasal PD (PDmax), time for PDmax to return to $50 \%$ of the baseline PD (t0.5) and the area under the curve (AUC) were compared using TWAOV followed by paired Student's t-tests where significant differences were seen. AUC was quantified using the statistical package Graphpad Prism 2.0 (Graphpad Software, Inc., San Diego, CA, USA), by calculation of the AUC which was presented as weighted means over $8 \mathrm{~h}$. Increases from baseline were recorded as zero. In all analyses a p-value $<0.05$ was regarded as statistically significant.

\section{Results}

Basal PD values were $-36.8 \pm 0.7 \mathrm{mV},-36.0 \pm 1.6 \mathrm{mV}$ and $-39.1 \pm 1.4 \mathrm{mV}$ on the benzamil, amiloride and placebo study days respectively $(\mathrm{p}=0.1$, NS). There was no order effect ( $p=0.1$, NS).

Benzamil had a similar maximum effect but a more prolonged action than amiloride (fig. 1). PDmax was 20.6 $\pm 0.9 \mathrm{mV}$ after benzamil, $20.3 \pm 1.6 \mathrm{mV}$ after amiloride and $3.6 \pm 2.3 \mathrm{mV}$ after placebo. TWAOV of PDmax, AUC and $t 0.5$ showed a significant difference between the three treatments (all $\mathrm{p}<0.0001$ ). PDmax values for amiloride and benzamil were significantly different from placebo

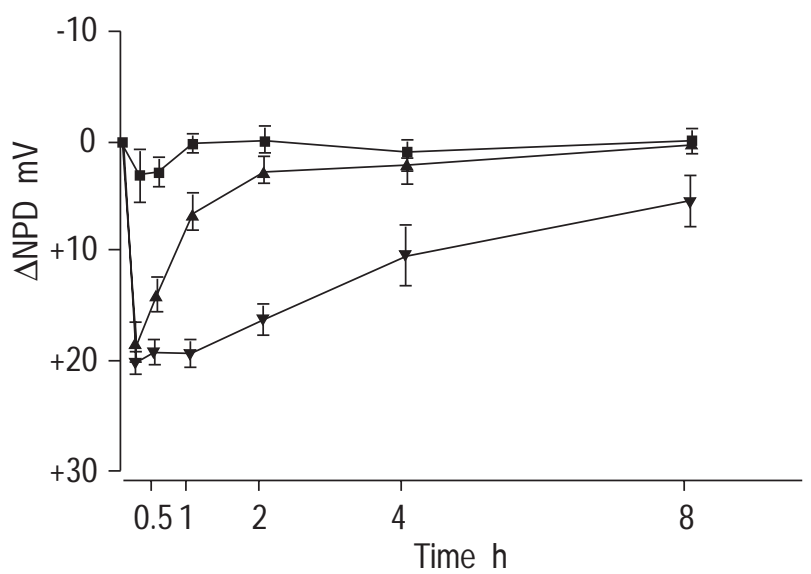

Fig. 1. - The effect of topically applied amiloride and benzamil or placebo on nasal potential difference (NPD) in 10 subjects with cystic fibrosis. Data are expressed as mean \pm SEM. $\triangle$ : change; $\boldsymbol{\square}$ : placebo; $\boldsymbol{\Delta}$ amiloride; $\boldsymbol{\nabla}$ : benzamil. 
(both $\mathrm{p}<0.0001$ ) but there was no significant difference between the amiloride and benzamil PDmax $(p=0.9)$. AUC values for benzamil, amiloride and placebo were 11.8 \pm 1.6 $\mathrm{mV}, 2.8 \pm 0.4 \mathrm{mV}$ and $0.6 \pm 0.4 \mathrm{mV}$, respectively. Both benzamil and amiloride were significantly different from placebo $(\mathrm{p}<0.0001$ and $\mathrm{p}<0.001$ respectively). The AUC value for benzamil was significantly greater than amiloride $(95 \%$ confidence interval $(\mathrm{CI})$ for the difference $5.3-12.7 \mathrm{mV}, \mathrm{p}<0.0001)$. $t 0.5$ values were $4.3 \pm 0.7 \mathrm{~h}$ for benzamil and $0.6 \pm 0.1 \mathrm{~h}$ for amiloride $(95 \% \mathrm{CI}$ for the difference $2.0-5.3 \mathrm{~h}, \mathrm{p}<0.001)$. There were no sideeffects reported in the study.

\section{Discussion}

In this double blind, placebo controlled crossover study it has been shown that benzamil and amiloride have a similar maximum effect on nasal PD but that the effect of benzamil is longer lasting. This suggests that benzamil has the potential to be a more useful sodium channel blocker than amiloride for the treatment of CF lung disease.

The magnitude of the basal PDs in the CF subjects were similar to those of a previous study [7]. The maximum effect (52\% increase from baseline) and short duration of action of amiloride in this study is similar to that previously reported $[6,7,10,18,20]$. The short duration of action of amiloride is likely to explain the lack of efficacy seen in studies of regular nebulized amiloride given either short ( 2 weeks) [10] or long-term (6 months) $[11,12]$ to the lungs in CF patients. Nebulized amiloride, given four times daily, could only be expected to block $\mathrm{ENaC}$ sodium channels for a fraction of the day.

The maximal effect of benzamil was similar to amiloride in this study. Benzamil produced a much more sustained increase in nasal PD than amiloride with a $t 0.5$ seven times greater than amiloride. The effect of benzamil was still $50 \%$ of maximal at $4 \mathrm{~h}$ and the PD had not returned to baseline at $8 \mathrm{~h}$ in contrast to amiloride where the effect was only $35 \%$ of maximum at $1 \mathrm{~h}$ and was negligible at $2 \mathrm{~h}$. These results suggest that regular administration of benzamil 3-4 times daily would be likely to produce a marked and sustained reduction in sodium reabsorption.

The only other study to compare the effect of amiloride and benzamil is an open parallel group pilot study by HoFMANN et al. [18]. In their study the maximal PD from baseline and duration of effect were measured for $6 \mathrm{~h}$ after different concentrations of amiloride and benzamil. Their findings, using the same concentration of amiloride $\left(10^{-3}\right.$ $\mathrm{M}$ ), were similar to those of the current study with a $t 0.5$ of $0.7 \mathrm{~h}$ compared to $0.6 \mathrm{~h}$ in the current study. Their results with benzamil were qualitatively similar to the current results, showing that it was longer acting than amiloride. There were, however, some quantitative differences. The present study found that the $t 0.5$, for benzamil $\left(1.7 \times 10^{-3}\right.$ M) was $4.2 \mathrm{~h}$ whereas in their study a four-fold greater concentration of benzamil was required to produce a similar effect (benzamil $7 \times 10^{-3} \mathrm{M}, t 0.5 .4 .5 \mathrm{~h}$ ). The reason for the quantitative differences between the current study and that of HOFMANN et al. [18] may be due to differences in study design. The present study was a double blind crossover design with changes in nasal PD between drugs being compared in the same subject whereas that of HoFMANN et al. [18] study had an open parallel group design where results were compared in different subjects, with different numbers of subjects in each group. Alternatively it may reflect differences in the delivery systems used. In the current study the drugs were applied topically via a nasal spray whereas in HOFMANN et al. [18] the drugs were nebulized. It would seem likely that administration of a drug directly, via a nasal spray, would deliver a more concentrated dose to the nasal epithelium than delivery via a nebulizer. Similar to HofMANN et al. [18], the current authors chose doses of amiloride and benzamil which were at the limit of their solubility in $0.9 \%$ sodium chloride. Saline was used as the placebo as previous work suggests that repetitive topical administration of isotonic saline has no effect on nasal PD [14, 21].

The present study showed a longer duration of action of benzamil on nasal PD but before it is used as a treatment for CF lung disease in clinical practice studies showing a similar increased duration of action in the lung are needed. Consideration will also need to be given to its toxicity. No side-effects were seen of nasally administered benzamil in this study but the toxicological consequences of administration of this drug to the lungs are unknown. Benzamil is more lipophilic than amiloride and this could potentially increase its systemic absorption and toxicity [8, 18]. Detailed pharmacological safety studies in animal models and humans will be necessary before benzamil can be used for the long-term treatment of CF lung disease.

There are several approaches which can be used to correct the biochemical defect in the CF lung. These include gene therapy $[22,23]$ and pharmacological agents which enhance chloride secretion [24-26], traffic CFTR to the apical membrane [27] or block sodium absorption [10-12]. Recent studies with gene therapy show a degree of correction of the chloride current but no correction of sodium reabsorption [23]. Similarly chloride channel openers such as widine triphosphate (UTP) do not correct the increased sodium absorption [24] suggesting that there may be added benefits of giving these agents in combination with sodium channel blockers. This may be particularly important with $\Delta$ F508 CFTR trafficking drugs as studies with sodium 4-phenylbutyrate have indicated that this may increase sodium absorption [28]. It seems likely that the greatest improvement in the biochemical defect and clinical course of CF lung disease will be seen when long acting sodium channel blockers are used in conjunction with pharmacological chloride channel openers, CFTR trafficking drugs, or gene therapy.

In conclusion, it has been shown that benzamil produces a more sustained improvement in nasal potential difference than amiloride in cystic fibrosis. Benzamil may therefore hold promise as a long acting sodium channel blocker for the treatment of cystic fibrosis lung disease. Further studies are needed to address the long term benefits and safety of benzamil given regularly by nebulization to the lower respiratory tract.

Acknowledgements. The authors would like to thank S. Lewis for statistical advice, and S. Pacey for randomizing the study.

\section{References}

1. Knowles MR, Gatzy JT, Boucher RC. Increased biolectric potential difference across respiratory epithelia in cystic fibrosis. N Engl J Med 1981; 305 (25): 1489-1495.

2. Boucher RC, Stutts MJ, Knowles MR. Na transport in 
cystic fibrosis respiratory epithelia: abnormal basal rate and response to adenylate cyclase activation. $J$ Clin Invest 1986; 78: 1245-1252.

3. Boucher RC, Cotton CU, Gatzy JT. Evidence for reduced $\mathrm{Cl}$ and increased Na permeability in cystic fibrosis human primary cell cultures. J Physiol 1988; 405: 77-103.

4. Knowles MR, Carson JL, Collier AM, Gatzy JT, Boucher RC. Measurements of nasal transepithelial electric potential differences in normal human subjects in vivo. Am Rev Respir Dis 1981; 124: 484-490.

5. Alton EWFW, Currie D, Logan Sinclair R, Warner J, Hodson ME, Geddes DM. Nasal potential difference: a clinical diagnostic test for cystic fibrosis. Eur Respir $J$ 1990; 3: 922-926.

6. Middleton PG, Geddes DM, Alton EWFW. Protocols for in vivo measurement of the ion transport defects in cystic fibrosis nasal epithelium. Eur Respir J 1994; 7: 20502056.

7. Peckham DG, Conn A, Chotai C, Lewis S, Knox AJ. Effect of oral digoxin, topical oubain and salbutamol on trans-epithelial nasal potential difference in patients with cystic fibrosis. Clin Science 1995; 89: 277-284.

8. Simchowitz L, Kleyman TR, Cragoe EJ. An overview of the structure - activity relations in the amiloride series. In: Cragoe EJ, Kleyman T, Simchowitz L, eds. Amiloride and its analogs - Unique cation transport inhibitors, New York VCH; 1992: 9-24.

9. Young S, Benos O, Benos DJ. Amiloride-Sensitive Sodium Channels. In: Cragoe EJ, Kleyman TR, Simcchowitz L, eds. Amiloride and its Analogs. Unique cation transport inhibitors, New York, VCH, 1992; 41-56.

10. Bowler IM, Kelman B, Worthington D, et al. Nebulised amiloride in respiratory exacerbations of cystic fibrosis: a randomised controlled trial. Arch Dis Child 1995; 73: 427-430.

11. Knowles MR, Church NL, Waltner WE, Yankakas JR, Gilligan P. A Pilot Study of aerosolized amiloride for the treatment of lung disease in cystic fibrosis. $N$ Engl J Med 1990; 322: 1189-1194.

12. Graham A, Hasani A, Alton EWFW, et al. No added benefit from nebulized amiloride in patients with cystic fibrosis. Eur Respir J 1993; 6: 1243-1248.

13. Mentz WM, Brown JB, Friedman M, Stutts MJ, Gatzy JT, Boucher RC. Deposition, clearance and effects of aerosolized amiloride in sheep airways. Am Rev Respir Dis 1986; 134: 938-943.

14. Middleton PG, Geddes DM, Alton EWFW. Effect of amiloride and saline on nasal mucociliary clearance and potential difference in cystic fibrosis and normal subjects. Thorax 1993; 48: 812-816.

15. App EM, King M, Helfesrieder R, Kohler D, Matthys $H$. Acute and long-term amiloride inhalation in cystic fibrosis lung disease. Am Rev Respir Dis 1990; 141: 605-612.
16. Knowles MR, Church NL, Waltner WE, Gatzy JT, Boucher RC. Amiloride in cystic fibrosis: safety, pharmacokinetics, and efficacy in the treatment of pulmonary disease. In: Cragoe EJ, Kleyman TR, Simchowitz L, eds. Amiloride and its Analogs - Unique Cation Transport Inhibitors. New York, VCH, 1992; 301-316.

17. Blank U, Clauss W, Weber WM. Effects of benzamil on human cystic fibrosis airway epithelium. Cell Physiol Biochem 1995; 5: 385-390.

18. Hodmann T, Stutts MT, Ziersch A, et al. Effects of topically delivered benzamil and amiloride on nasal potential difference in cystic fibrosis. Am J Respir Crit Care Med 1998; 157: 1844-1849.

19. Middleton PG, Caplen NJ, Gao X, et al. Nasal application of cationic liposome DC-Chol:DOPE does not alter ion transport, lung function or bacterial growth. Eur Respir $J$ 1994; 7: 442-445.

20. Waltner WE, Church NL, Gatzy JT, Boucher RC, Knowles MR. Deposition, pharmacokinetics and toxicity of amiloride aerosol in normal and cystic fibrosis subjects. Am Rev Respir Dis 1987; 135: A288.

21. Hoffman T, Boy CE, Robinson JM, Homely V, Butcher RC, Knolls MR. Dexamethasone increases sodium transport in human nasal epithelium in vivo. Pediatr Pulmonol 1997; 14: 234.

22. Knowles MR, Hohneker KW, Zhou Z, et al. A controlled study of adenoviral-vector-mediated gene transfer in the nasal epithelium of patients with cystic fibrosis. $N$ Engl $J$ Med 1995; 333: 823-831.

23. Caplen NJ, Alton EWFW, Middleton PG, et al. Liposome-mediated CFTR gene transfer to the nasal epithelium of patients with cystic fibrosis. Nature Med 1995; 1: 39-46.

24. Knowles MR, Clarke LL, Boucher RC. Activation by extracellular nucleotides of chloride secretion in the airway epithelia of patients with cystic fibrosis. $N$ Engl $J$ Med 1991; 325: 533-538.

25. Knowles MR, Clarke LL, Boucher RC. Extracellular ATP and UTP induce chloride secretion in nasal epithelia of cystic fibrosis patients and normal subjects in vivo. Chest 1992; 101 (3): 60S-63S.

26. Eidelman O, Guay-Broder C, Van Galen PJM, et al. A1 adenosine-receptor antagonists activate chloride efflux from cystic fibrosis cells. Pro Natl Acad Sci 1991; 89: 5562-5566.

27. Rubenstein RC, Zeitlin PL. A pilot clinical trial of oral sodium 4 Phenylbutyrate (Buphenyl) in delta F508 Homozygous cystic fibrosis patients. Am J Respir Crit Care Med 1998; 157: 484-490.

28. Cheng SH, Fang SL, Zabner J, et al. Functional activation of the cystic fibrosis trafficking mutant Delta F508CFTR by overexpression. Am J Physiol 1995; 268: L615-L624. 